\title{
Message from the 2019 Program Chair
}

Published online: 3 December 2019

(C) International Association of Medical Science Educators 2019
Dear friends and colleagues,

The 23rd annual meeting of the International Association of Medical Science Educators was held in the beautiful setting of Hotel Roanoke in Roanoke, Virginia. The location for the meeting was truly splendid with Hotel Roanoke providing a relaxing setting that merged the modern benefits of a contemporary hotel, while preserving its long-standing traditions and history. Set amongst the wild surroundings of the Blue Ridge Mountains and being only a stone's throw from downtown Roanoke, colleagues and friends convened from around the world for the 2019 IAMSE meeting around our theme: "Adapting to the Changing Times in Health Sciences Education," which was hosted by Virginia Tech Carilion School of Medicine.

The 2019 meeting can only be described as a success with registration numbers continuing to rise and the quality of the plenary speakers providing the prompt for interesting, challenging, and thought-provoking conversation between attendees. Health science education is continually evolving and with the focus of the meeting on the ever-changing landscape of health science education, including the latest changes in foundational science delivery, educational technology, and changing demographics; all participants learnt and were able to share the latest thinking in this educational space. In addition to these highlights, the meeting held a wide range of opportunities, where colleagues could share their own scholarly practices and participate in conversations to support their own development. Through a wide range of pre-conference workshops, focus sessions, oral presentation, and posters, colleagues had a number of opportunities to enhance their own professional practice and ultimately enhance the learning experience of healthcare students - our future healthcare practitioners.

This issue of Medical Science Educator draws together words from our plenary speakers in addition to the abstracts from our meeting's oral and poster submissions. Moreover, it provides a window into the ongoing mission of IAMSE through its journal to allow members and colleagues from around the world to share experiences, reconnect, collaborate, network, and learn from each other. Together, the meeting and journal deliver the vision and expanding international mission of IAMSE, which is to advance health science education through teacher and faculty development, ensuring that the learning and teaching of foundational science continues to be the cornerstone of health science education around the world. On behalf of the 2019 Program Planning Committee, IAMSE staff, Board of Directors, the Executive Committee, and especially the efforts of the Student Professional Development Committee, this year we benefited from the participation of a record number of students and welcomed them to the association as future colleagues.

A special mention should be made to the recipients of the IAMSE Distinguished Career Award for Excellence in Teaching and Educational Scholarship, the Early Career Award for Excellence in Teaching and Innovation, and the Student and Faculty Travel awards and the winners of the best Oral and Poster Presentations. These awards truly represent the outstanding accomplishments and contributions of our members. In addition, we recognized Gary Rosenfeld, $\mathrm{PhD}$, with the Edward Patrick Finnerty Lifetime Achievement Award for his sustained involvement in and commitment to the advancement of IAMSE. In addition, future education leaders participated in the Essential Skills in Medical Education (ESME) Program and Educational Scholarship Fellowship Program.

IAMSE's members are international leaders, innovators, and scholars in health sciences education. The work presented in this issue represents evidence-informed curricula, instructional strategies, assessment methods, faculty development, and technology for teaching. We hope they inspire you in your own academic and scholarly efforts. Please join us for our next annual meeting June 13-16, 2020, in Denver, CO, USA. We look forward to seeing you there!

James Pickering, $\mathrm{PhD}$

2019 Program Chair 